\title{
A Study of Farmers' Awareness About Climate Change and Adaptation Practices in India
}

\author{
Rupan Raghuvanshi, Mohammad Aslam Ansari , Amardeep \\ Department of Agricultural Communication, Govind Ballabh, Pant University of Agriculture \& Technology, Pantnagar, India \\ Email address: \\ rupanraghuvanshi17oct@gmail.com (R. Raghuvanshi), aslam1405@yahoo.com (M. A. Ansari), chauhanadeep@gmail.com (Amardeep)
}

\section{To cite this article:}

Rupan Raghuvanshi, Mohammad Aslam Ansari, Amardeep. A Study of Farmers' Awareness About Climate Change and Adaptation Practices in India. International Journal of Applied Agricultural Sciences. Vol. 3, No. 6, 2017, pp. 154-160. doi: 10.11648/j.jjaas.20170306.13

Received: October 17, 2017; Accepted: November 6, 2017; Published: December 5, 2017

\begin{abstract}
Agriculture is the backbone of Indian economy, and climate change significantly affects agriculture productivity. The present study was conducted in one district of Uttarakhand state in the North Himalayan region of India bordering Nepal and China. The study sample comprised 110 farmers selected by using simple random sampling. Study findings indicate that all the farmers were found to be aware of the climate change, and majority of them reported "erratic rainfall, diminishing agricultural yield and increase in temperature" as the indicators of climate change. The increasing industrialisation, overpopulation and deforestation' were perceived by farmers to be the main causes of climate change. Further, most of the farmers reported crop failures, migration to other places and flooding' as three major consequences (impact) of climate change. The study findings will help in preparing a roadmap for policy formulation as well as undertaking mitigation measures besides helping the agriculture extension agencies to design and plan locale specific adaptation strategies and agriculture development programmes.
\end{abstract}

Keywords: Climate Change, Awareness About Climate Change, Climate and Hill Agriculture, Climate Change Adaptation, Farming in Mountain Ecosystem

\section{Introduction}

The United Nations Framework Convention on Climate Change (UNFCCC) defined "Climate change" as a change which is attributed directly or indirectly to human activity that alters the composition of the global atmosphere. Agriculture is inherently sensitive to climatic changes and is one of the most vulnerable sectors [1]. Climate change directly affects agriculture production and production efficiency. It affects agriculture in terms of productivity, agricultural practices, environmental effects, rural space, and adaptation. Adebayo et al [2] reported that majority of the farmers (95\%) claimed that climate change has affected their farming activities, reduced crop yield, shortage of water and biomass for animals due to low rainfall and frequent dry spells in the last ten years, while only $5 \%$ of the respondents reported not to be affected by climate change in recent years. Small scale poor farmers suffer most because of small landholdings and lack of resources to cope up with climate change. Poor rural households, whose livelihood depend predominantly on agriculture and natural resources bear a disproportionate burden of adverse impact of climate change [3] [4] [5].

The key impact of climate change in the state of Uttarakhand (India) will be the faster retreat of Himalayan glaciers, frequent floods and decrease in crop yield and increased frequency of extreme weather events such as cloud bursts, flash floods, extended rainfall, increased temperatures, heavy snowing, etc. Consequently, production of food grains such as wheat will be negatively impacted in Rabi season due to terminal heat stress; and Rice will be affected both by rising temperature levels and water availability. The productivity of most cereals would decrease due to increase in temperature and $\mathrm{CO}_{2}$, and decrease in water availability. It will reduce farmer's income and farm profitability. Besides, it will also have negative impact on the food security and also affect its availability.

Climate change is therefore an issue of great concern to all countries irrespective of their size or level of development. In Asia, agricultural crop yield is expected to decline by $5-30 \%$ by $2050 \mathrm{~s}$ due to rising temperatures; and this decline in agricultural yield will lead to food insecurity, which will become a serious future problem for human being. In India, it 
has been projected that $2.5^{\circ} \mathrm{C}$ to $4.9^{\circ} \mathrm{C}$ rise in temperature in India will lead to $32 \%-40 \%$ drop in rice yields and $41-52 \%$ in wheat. This would cause GDP to fall by $1.8 \%-3.4 \%$ [6] [7] [8].

Therefore, climate change is the biggest threat to agriculture in India but still the farmers are not fully aware of climate change and its indicators, causes, and impacts. Sarkar and Padaria [9] in a study in West Bengal reported that only 38 per cent of the farmers had heard about climate change and a large number are not aware of the phenomena of climate change. Farmers experienced the changing climatic conditions in their life but they are still not aware about the term climate change. Adewale and Owolade [10] in a study found that 87.5 percent of farmers have heard about climate change whereas Sogani [11] reported that communities in the mountain areas of Uttarakhand are well aware that weather is changing. Temperatures are more variable, periods of drought are longer, rainfall is erratic, some plant species are flowering earlier, there is a vertical shifting of trees and crops, some natural resources are disappearing, and new and unfamiliar pests and diseases are emerging.

Agriculture in hilly areas of Uttarakhand is largely rainfed, irrigation facilities are minimal, and land holdings are small and fragmented. The region also suffers on account of heavy soil erosion and significantly lower yields as compared to the national average. Hence, Uttarakhand is very vulnerable to climate-mediated risks. To cope up with changing climate, there had been a change in agronomic practices and varieties to cope up with it. A better understanding of how farmers' perceive changing climate and the factors influencing the awareness level of farmers is needed to formulate appropriate policies and programmes aimed at promoting successful awareness of farmers and adaptation strategies to cope up with climate change.

In order to gather insight into these issues, the present research study was undertaken to find out farmer's awareness about climate change, their knowledge about the indicators of climate change and adaptation measure to minimise the negative impact of agriculture productivity.

\section{Material and Methods}

The study was conducted in a purposively selected district (Tehri Garhwal) in North Himalayan state of Uttarakhand in India as this has been designated as one of the most vulnerable district [12]. The state of Uttarakhand lies between longitude $77056^{`}$ and $79004^{\prime} \mathrm{E}$ and latitude $3003^{`}$ and $30053^{\prime}$ N.A total of 110 farmers were selected randomly from two villages (Dabri and Kalheth) in the selected district. Data was collected using a pre-tested structured interview schedule and were analysed using SPSS. The farmers were personally interviewed by the researcher.

\section{Results and Discussion}

\subsection{Socio-economic Profile of the Farmers}

A socio-economic profile of the respondents is presented in Table 1.

Table 1. Distribution of respondents according to their socio-economic characteristics.

\begin{tabular}{|c|c|c|c|}
\hline SI. No & Variables & Frequency & Percentage \\
\hline \multirow{4}{*}{1.} & Age (Year) & & \\
\hline & Young (Less than 45) & 45 & 40.90 \\
\hline & Middle aged (45 to 67 ) & 56 & 50.90 \\
\hline & Old (More than 67) & 9 & 8.20 \\
\hline \multirow{3}{*}{2.} & Gender & & \\
\hline & Male & 50 & \\
\hline & Female & 60 & 45.45 \\
\hline \multirow{4}{*}{3.} & Landholding & & 54.55 \\
\hline & Small farmer (1-3 Acres) & 88 & 80 \\
\hline & Medium farmer (3-5 Acres) & 15 & 13.63 \\
\hline & Large farmer (More than 5 acres) & 7 & 6.37 \\
\hline \multirow{7}{*}{4.} & Education & & \\
\hline & Illiterate & 21 & 19.45 \\
\hline & $\begin{array}{l}\text { Functionally literate (Able to read } \\
\text { and write only) }\end{array}$ & 4 & 3.64 \\
\hline & Primary education & 35 & 31.85 \\
\hline & High school & 18 & 16.89 \\
\hline & Intermediate & 28 & 24.53 \\
\hline & Graduate & 4 & 3.64 \\
\hline \multirow{4}{*}{5.} & Socio Economic Status & & \\
\hline & Upper class & 3 & 2.72 \\
\hline & Middle class & 64 & 58.19 \\
\hline & Lower class & 43 & 39.09 \\
\hline \multirow{4}{*}{6.} & Information seeking behaviour & & \\
\hline & Low & 9 & 8.18 \\
\hline & Medium & 87 & 79.09 \\
\hline & High & 14 & 12.73 \\
\hline \multirow{4}{*}{7} & Decision making ability & & \\
\hline & Low & 37 & 33.63 \\
\hline & Medium & 57 & 51.83 \\
\hline & High & 16 & 14.54 \\
\hline \multirow{4}{*}{8.} & $\begin{array}{l}\text { Attitude towards improved farm } \\
\text { practices }\end{array}$ & & \\
\hline & Unfavourable & 13 & 11.81 \\
\hline & Moderately favourable & 64 & 58.19 \\
\hline & Highly favourable & 33 & 30 \\
\hline \multirow{4}{*}{9.} & Economic motivation & & \\
\hline & Low (Less than 15) & 32 & 29.09 \\
\hline & Medium (15 to 21$)$ & 18 & 16.36 \\
\hline & High (More than 21) & 60 & 54.55 \\
\hline \multirow{4}{*}{10.} & Scientific orientation & & \\
\hline & Low & 35 & 31.81 \\
\hline & Medium & 19 & 17.27 \\
\hline & High & 56 & 50.92 \\
\hline
\end{tabular}

As is evident from the above table, majority of the farmers in study sample were middle-aged, females, educated up to primary \& high school (about $48 \%$ ), and one-fourth educated up to intermediate, were small holders, belonging to middle class, having 'medium' information seeking behaviour, and had 'medium' decision making ability. Further, they displayed 'moderately' favourable attitude towards improved farm practices, along with high' economic motivation, and 'high' scientific motivation.

\subsection{Awareness About Climate Change}

All the farmers $(100 \%)$ in the study sample reported that they are well aware of the climate change. Further, when probed about the level of awareness about climate change, 
half of the respondents (50\%) displayed 'medium' level of awareness about climate change followed by 27.28 percent who had 'low' awareness level, and only 22.72 percent of respondents had 'high' level of awareness about climate change. Raghuvanshi and Ansari [19] reported that to cope up with climate change depends on level of awareness about climate change. Farmers who are aware about the climate change, its causes and consequences are more likely to adopt adaptation measures and mitigation practices to cope up with adverse effects of climate change.

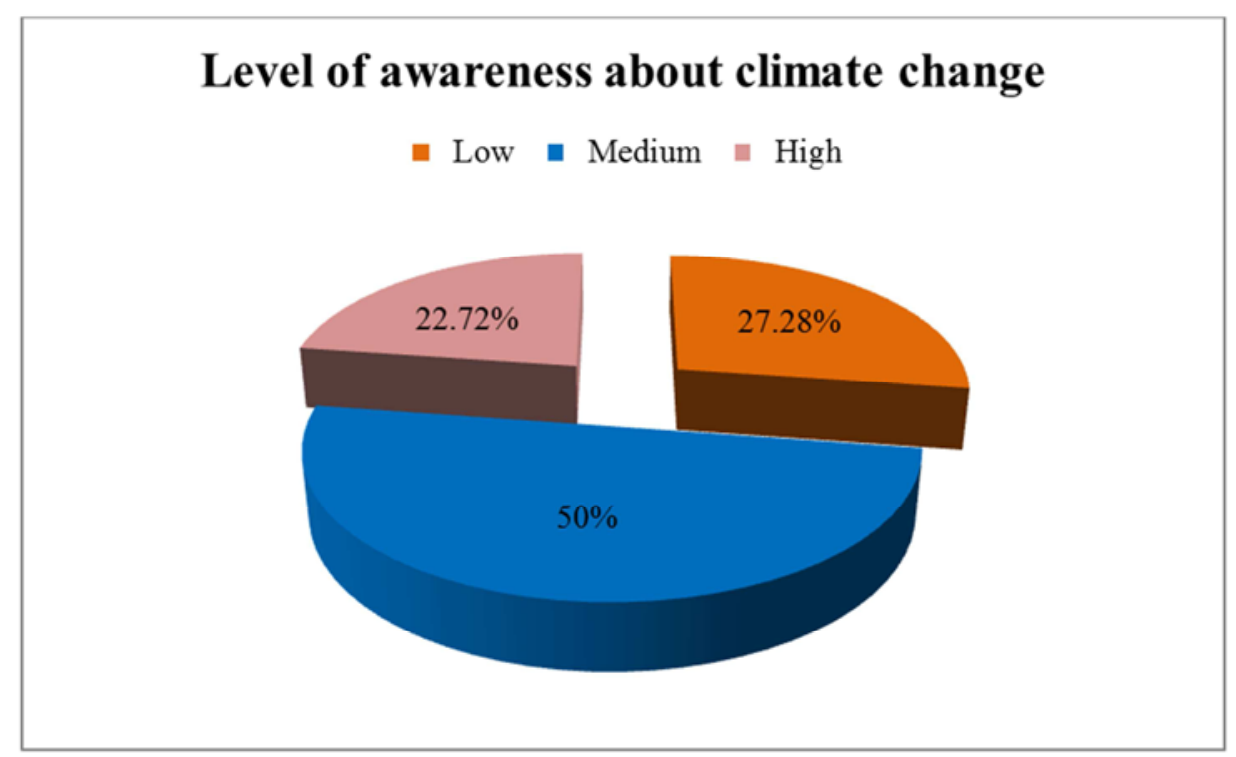

Figure 1. Farmer's awareness about climate change $(n=110)$.

These findings are also supported by Adebayo et al. [2] who observed that large majority of the respondents (about $96 \%$ ) were aware of climate change, while only about 4 percent seemed not to be aware of climate change. Sogani [11] in a study of documentation of climate change perceptions and adaptation practices in Uttarakhand reported that communities in the mountain areas are well aware that the weather is changing. Tripathi and Singh [13] in a study on perception, anticipation and responses of people to changing climate in the Gangetic plains of India observed that only 30 percent of respondents were aware of the term climate change.

\subsection{Awareness About Indicators of Climate Change}

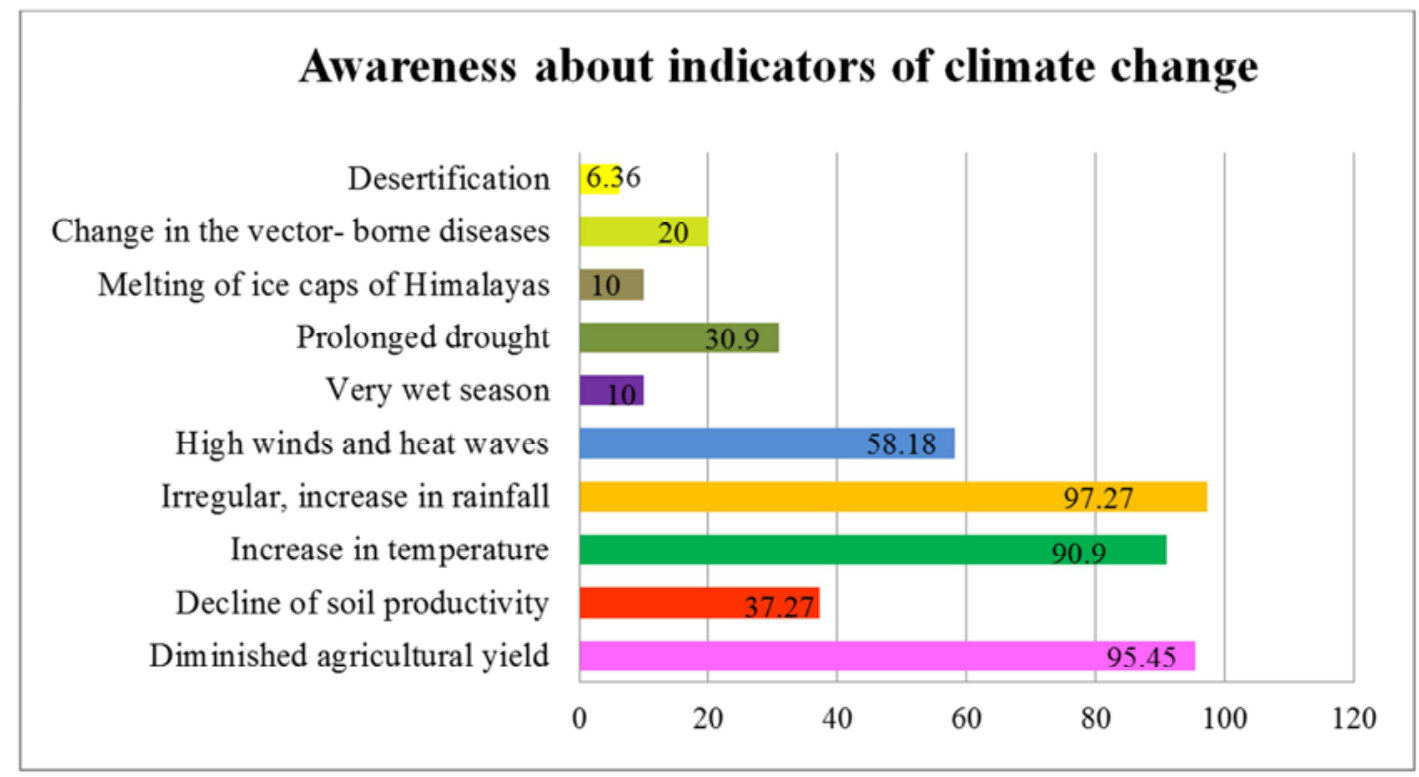

Figure 2. Farmer's awareness about indicators of climate change $(n=110)$.

Farmers, when asked whether they are aware of the indicators of climate change, a large majority of them
(97.27\%) mentioned 'irregular, untimely and increase in frequency of extreme rainfall' as one of the major indicator 
of climate change. Further, 'diminished agricultural yield' was reported as another indicator of climate change by $95.45 \%$ followed by 90.90 percent reporting 'increase in temperature' as an indicator of climate change. Some other indicators reported by respondents were 'high winds and heat waves', 'decline of soil productivity', and 'prolonged drought'. Change in vector born diseases, very wet season and melting of ice caps of Himalayas were also mentioned by 20 and $10 \%$ respondents, respectively as other indicators of climate change; and only 6.36 percent of respondents stated desertification as an event that indicates the climate change.

From the above findings, it may be concluded that majority of the respondents could identify major indicators of climate change in the form of diminished agricultural growth, irregular, untimely and increase in frequency of extreme rainfall, increase in temperature, high winds and heat waves. This may be due to the fact that these changes are more observable and are being experienced by the farmers. The study also finds support from the findings of Kemausuor et al. [14] who reported that large majority (93\%) of farmers were of the opinion that the timing of the rains is now irregular and unpredictable; and also supported by Baul et al [15] who observed that 84 percent of farmers perceived that temperatures have increased. The study findings are also supported by Legesse et al. [16] found that 95 percent of sample households perceived increases in frequency of occurrence of drought.

\subsection{Awareness About Causes of Climate Change}

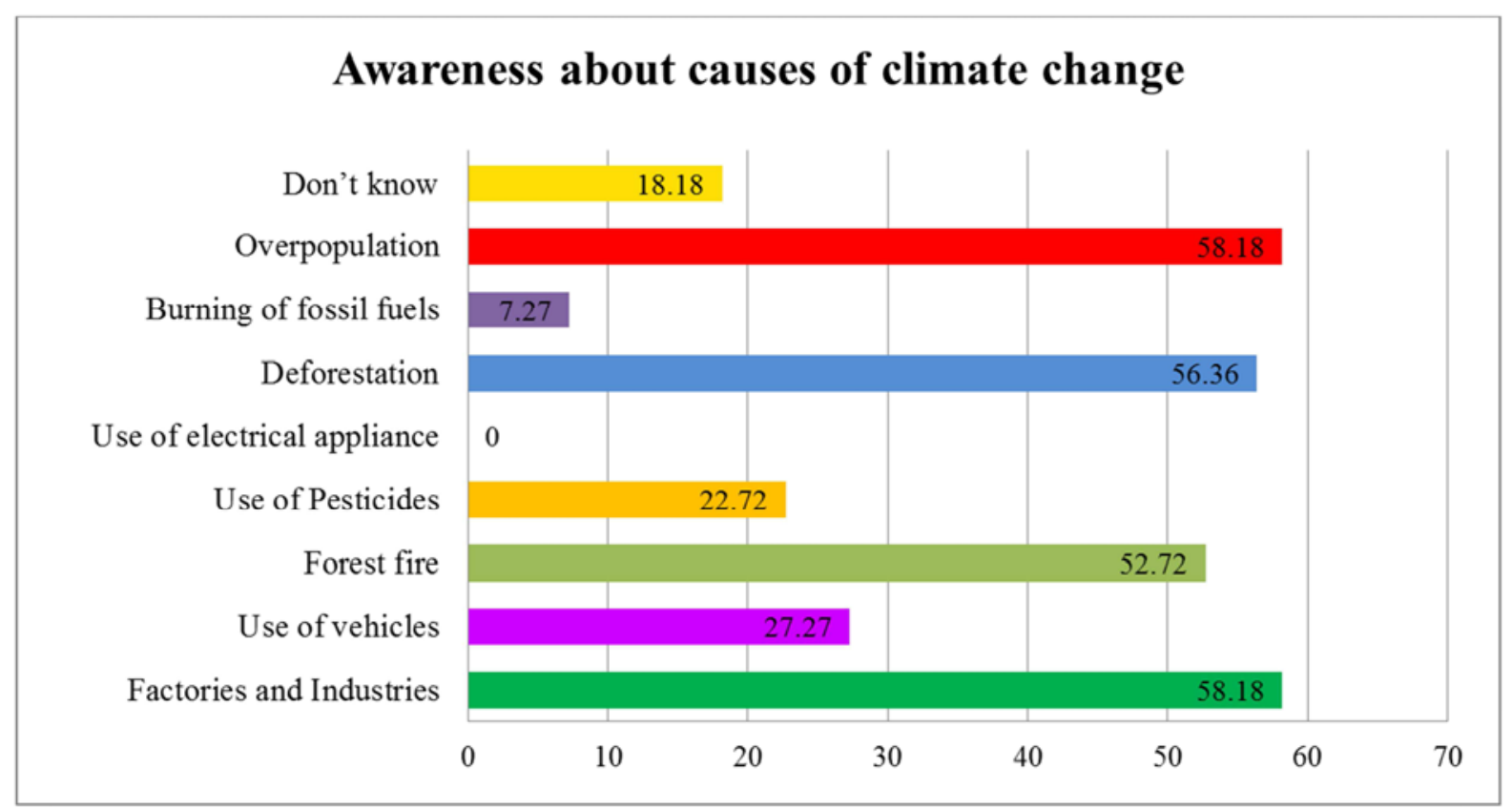

Figure 3. Farmers awareness about causes of Climate change $(n=110)$.

Awareness of causes of climate change among the farmers is critical for undertaking adaptation measures to cope-up with climate change. The study findings indicate that majority of the farmers $(58.18 \%)$ reported 'factories, industries' and 'overpopulation' as two major causes of climate change. 'Deforestation' and 'Forest fire' were also reported as cause of climate change by 56.36 and 52.72 percent, respectively. The other causes reported by the respondents were 'use of motor vehicles, pesticides, and burning of fossil fuels. However, none of the respondents reported 'use of electrical appliance' as a cause of climate change. About $18.18 \%$ respondents did not know about the causes of climate change.

This indicate that majority of the farmers were aware about different causes of climate change i.e. industrialisation, overpopulation, forest fire, deforestation, etc. This is may be due to the fact that causes reported by the respondents are more observable by the people and the study area being hilly, so people could easily observe the adverse effects of the forest fire and deforestation in the hills. Further, media is also actively contributing in raising the awareness about the various causes of climate change. Few people did not know about the causes of climate change, and this reflects that still a fair number of people lack information on climate change in the study area.

Sarkar and Padaria [9] in a study on farmer's awareness and risk perception about climate change in West Bengal reported that nearly 38 per cent of the respondents had heard about climate change. Above two-third of them attributed climate change to industrialisation, while about three-fifth of them said that major factors for climate change were increase in deforestation, heavy use of transportation and use of oilbased motor boat for fishing and communication in the area. Adebayo et al. [2] in a study on farmers' awareness, vulnerability and adaptation to climate change in Nigeria found that large majority of the respondents(about 96\%) are aware of climate change. Further, Tripathi and Singh [13] in 
a study on perception, anticipation and responses of people to changing climate in the Gangetic plain of India observed that only 30percent of respondents were aware of the term climate change, 76 percent had positive perceptions about the effects of climate change.

\subsection{Awareness About Impact of Climate Change}

Majority of farmers $(80.90 \%)$ reported 'crop failure' followed by $72.72 \%$ of farmers who reported 'migration of the people to other places' as the two major impacts due to climate change. The other factors were 'flooding' as a result of climate change' reported by $30.90 \%$, extinction of plant species by $26.36 \%$, human disease outbreaks by $20 \%$. However, only $17.27 \%$ of farmers did not know about the impacts of changing climate on farming.

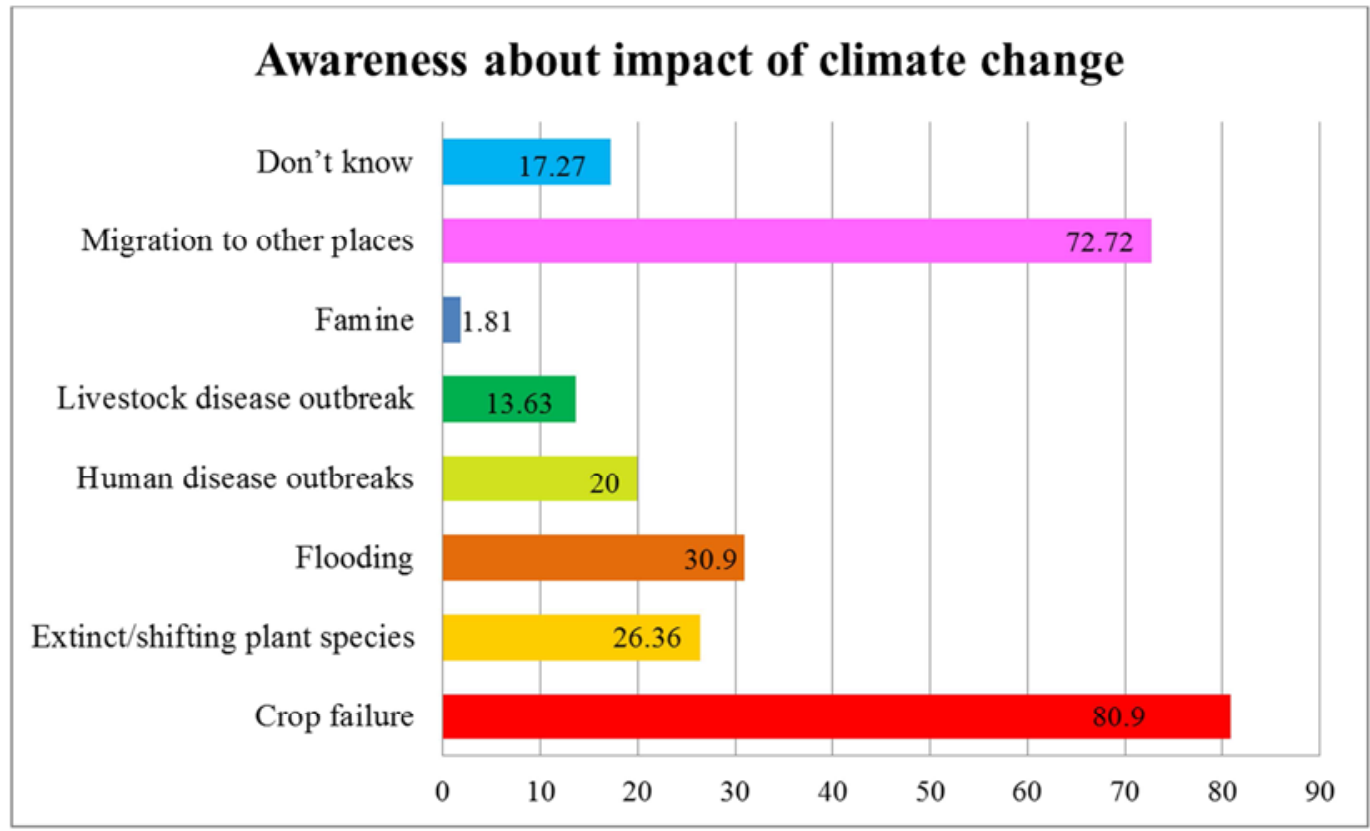

Figure 4. Farmers awareness about impact of climate change $(n=110)$.

Majority of the farmers had agriculture as their occupation so they have experienced the changes themselves in their farming practices due to climate change. These findings are supported by Sogani [11] who found that some plant species are flowering earlier, there is a vertical shifting of trees and crops, some natural resources are disappearing, and new and unfamiliar pests and diseases are emerging.

\subsection{Adaptation in Farming Practices}

There were certain types of adaptation practices that were practiced by farmers in order to cope up with the adverse impact of climate change. Results obtained are presented in Figure 5 below.

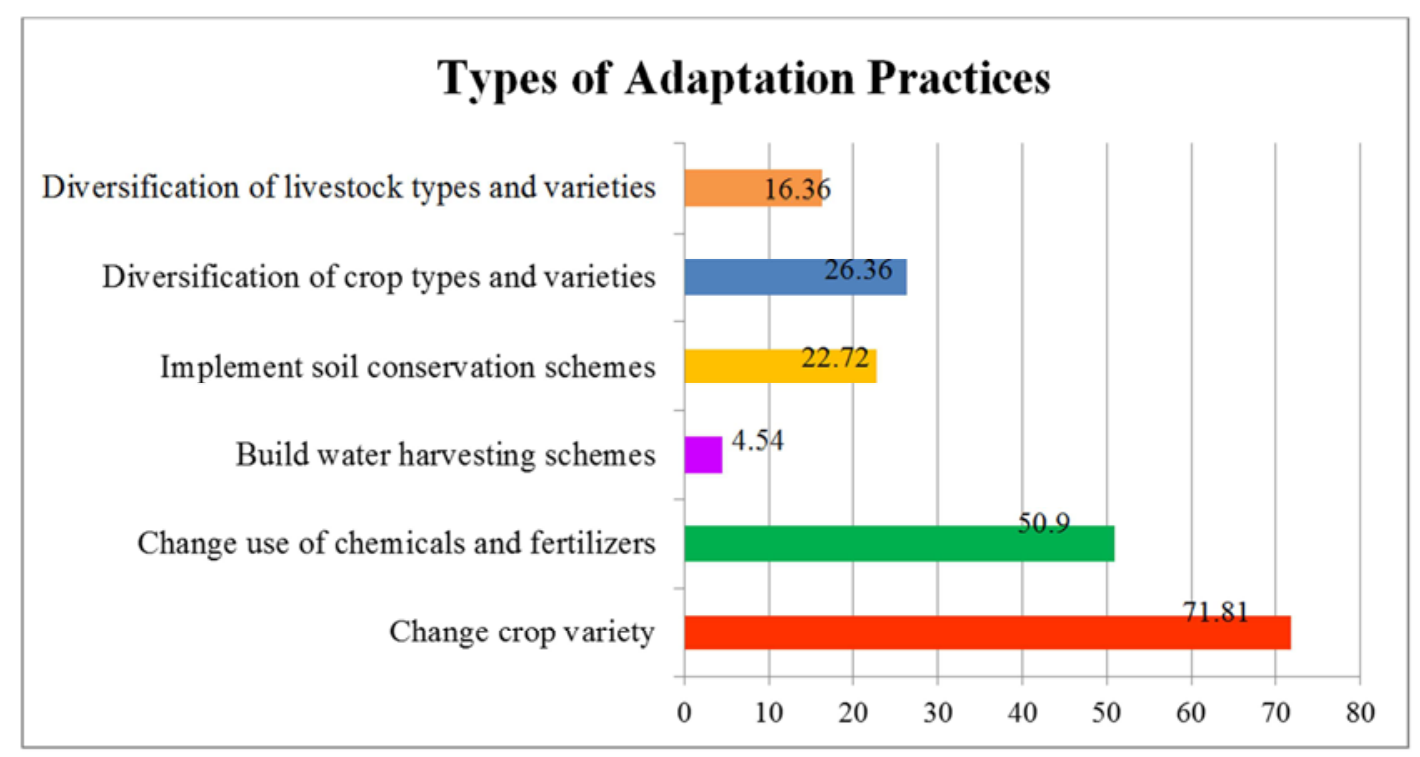

Figure 5. Distribution of farmers on the basis of type of adaptation practices. 
The study findings indicated that majority of the respondents $(71.81 \%)$ had changed their crop varieties followed $50.90 \%$ who made changes in use of chemicals and fertilizers. Other adjustments/adaptation practices as reported by the farmers were: diversification of crop types and varieties $(26.36 \%)$, implement soil conservation schemes $(22.72 \%)$. Further, only 4.54 percent of respondents built water harvesting structure to cope up with adverse impact of climate change. These findings are supported by Gbetibouo [17] that building water-harvesting schemes is a popular adaptation strategy (adopted) by those experiencing the effects of decreased precipitation. Dhanya and Ramchandran [18] observed that Climate change is recognised as one of the leading challenges affecting the performance of agriculture and the livelihood of people. Farmers are the hardest hit as they have to continuously respond to climatic variations. Farmers have indicated their specific adaptation needs, a number of which could be incorporated into site-specific adaption strategies and policies.

\subsection{Relationship Between Characteristics of Farmers and Their Level of Awareness Towards Climate Change}

The coefficient of correlation was calculated to find out the relationship between selected characteristics of the farmers with their level of awareness towards climate change and the significance of coefficient of correlation was tested using ttest.

Data regarding correlation between selected socioeconomic, personal and psychological characteristics comprising age, size of landholdings, education, occupation of the head of family, family income, social participation, SES, farming experience, information seeking behaviour, mass media exposure, attitude towards improved farm practices, attitude towards soil \& water conservation practices, attitude towards research station, economic motivation, scientific orientation and their level of awareness towards climate change is presented in the table-2.

Table 2. Correlation between level of awareness about climate change and independent variable.

\begin{tabular}{|c|c|c|c|}
\hline \multirow[t]{2}{*}{ S. No. } & \multirow[t]{2}{*}{ Variables } & \multicolumn{2}{|c|}{$\begin{array}{l}\text { Level of awareness } \\
\text { towards climate change }\end{array}$} \\
\hline & & $\mathbf{r}$ & t \\
\hline 1. & Age & -0.01 & -0.08 \\
\hline 2. & Size of landholding & $0.19 * *$ & 2.13 \\
\hline 3. & Education & $0.38^{*}$ & 4.29 \\
\hline 4. & Socio-Economic status & $0.24^{*}$ & 2.58 \\
\hline 5. & Information seeking behaviour & $0.47^{*}$ & 5.54 \\
\hline 6. & Decision making ability & $0.47 *$ & 5.54 \\
\hline 7. & $\begin{array}{l}\text { Attitude towards improved farm } \\
\text { practices }\end{array}$ & $0.54 *$ & 6.67 \\
\hline 8. & $\begin{array}{l}\text { Attitude towards soil \& water } \\
\text { conservation practices }\end{array}$ & $0.41 *$ & 4.68 \\
\hline 9. & Economic motivation & $0.38^{*}$ & 4.29 \\
\hline 10. & Scientific orientation & $0.56^{*}$ & 7.00 \\
\hline
\end{tabular}

$3 *=$ significance at 0.01 level of significance; $* *=$ significance at 0.05 level of significance; $\mathrm{t}_{\mathrm{tab}}=2.57$ ( $1 \%$ level of significance); $\mathrm{t}_{\mathrm{tab}}=1.96$ ( $5 \%$ level of significance)
As it is evident from the above table that out of ten independent variables selected to study the relationship with level of farmer's awareness towards climate change, all the variables except age were found to have positive (and significant) relationship with the dependent variable, i.e. farmer's level of awareness. Further, one variables, i.e. size of landholding - was found to have significant positive relationship with farmer's level of awareness at 1percent level of significance, and the remaining eight variables were found to be significant at 5\% level of significance. It may be due to the fact that farmer who possessed large landholding observed more changing climatic conditions because of more observable changes in their fields. Thus, education, socio-economic status, information seeking behaviour, decision making ability, attitude towards improved farm practices, attitude towards soil \& water conservation practices, attitude towards research station, economic motivation and scientific orientation displayed a significant positive relation with the level of awareness towards climate change. On the other hand age of the farmers' age was negatively related with the level of awareness towards climate change, which may be indicative of the differences of opinion between two generations of farmers.

\section{Conclusion}

Climate change has emerged as the primary determinant of agricultural productivity. Climate changes and extreme weather events strongly influence agriculture which in turn will threaten national food security. The degree, frequency, and nature of climatic changes can have serious consequences for agriculture and farming practices. Climate variability can force the farmers to adopt new practices such as shifting sowing time, land preparations, length of growing time, time of harvesting, and control \& management of insect-pests and diseases. Hence, farmers' perception about climate change, its causes, impact and indicators are of critical importance thereby helping them in coping-up with negative impact of climate change on agriculture productivity.

The study findings have reiterated this emphatically and underlined the importance for the extension agencies/ workers in planning for the appropriate corrective measures and re-orienting their advisory services to mitigate the climate change related risks and uncertainties. We need to provide location-specific and need-based information to farmers which will help in decision making at grassroots level. The need of the hour is to empower the farming community so that they evolve suitable mechanism for short term and long term adaptation strategies to take care of climate change related risks and uncertainties. 


\section{References}

[1] Parry, M., Rosenzweig, C. and Livermore, M (2005) Climate change, global food supply and risk of hunger. PhilTrans $R$ Soc B, 360, 2125-2136.

[2] Adebayo, A. A., Onu, J. I., Adebayo, E. F. and Anyanwu, S. O. (2012). Farmers' awareness, vulnerability and adaptation to climate change in Adamawa State, Nigeria. British Journal of Arts and Social Sciences, 9(11):104-113.

[3] Satapathy, S. (2011). Adaptation to Climate Change with a Focus on Rural Areas and India. Deutsche Gesellschaft für Internationale Zusammenarbeit (GIZ) GmbH, India. Project on Climate Change Adaptation in Rural Areas of India.

[4] Mendelsohn, R., A. Basist, F. Kogan, and P. Kurukulasuriya. (2007) Climate analysis with satellite versus weather station data. Climate Change, 81:71-83.

[5] Kates, R. (2000). Cautionary tales: Adaptation and the global poor. Climatic Change, 45(1): 5-17.

[6] Government of India. 2011: Agriculture. Accessed online at http://india.gov.in/sectors/agriculture/index.php

[7] Guiteras, R. (2007). The impact of climate change on Indian agriculture. Accessed online at http://hpccc.gov.in/PDF/Agriculture/The\%20Impact $\% 20$ of $\% 2$ 0Climate $\% 20$ Change $\% 20$ on\%20Indian\%20Agriculture.pdf

[8] OECD (Organisation for Economic Cooperation and Development). 2002: Climate Change: India's perceptions, positions, policies and possibilities.

[9] Sarkar, S. and Padaria, (2010). R. N. Farmers awareness and risk perception about climate change in coastal Ecosystem of west Bengal. Indian research journal of extension education 10(2): 32-38.

[10] Adewale, O. Adetayo and Owolade, Esther O. (2012). Climate change and mitigation awareness in small farmers of Oyo state in Nigeria. Open Science Repository Agriculture, doi: 10.7392/Agriculture.70081902
[11] Sogani R. BeejBachao Andolan (Save Seed Campaign). 2011. Documentation of climate change perceptions and adaptation practices in Uttarakhand. Northern India, 2011.33p. Available on http://www.panap.net/sites/default/files/06-CC-Phase1BBA.pdf assessed on 9/10/2014.

[12] CRIDA. (2013). Atlas on Vulnerability of Indian Agriculture to Climate Change. National Initiative on Climate Resilient Agriculture, Central Research Institute for Dryland Agriculture, Hyderabad. P 116.

[13] Tripathi, A. and Singh, G. S. (2013). Perception, anticipation and responses of peopleto changing climate in the Gangetic plains of India. Current Science, 105(12):25.

[14] Kemausuor, F., Dwamena, E., Plange, A. B. and Baffour, N. K. (2011). Farmers' perception of climate change in the EjuraSekyedumase District of Ghana. ARPN Journal of Agricultural and Biological Science 6 (10):26-37.

[15] Baul, T. K., Ullah, K. A., Tiwari, K. R. and McDonald, M. A. (2013). People's local knowledge of climate change in the middle hills of Nepal. Indian Journal of Traditional Knowledge 12 (4): 585-595.

[16] Legesse, B., Ayele, Y. and Bewket, W. (2013). Smallholder farmers' perceptions and adaptation to climate variability and climate change in Doba district, west Hararghe, Ethiopia. Asian Journal of Empirical Research 3(3):251-265.

[17] Gbetibouo, G. A. (2009). Understanding farmers' perceptions and adaptations to climate change and variability. International Food Policy Research Institute (IFPRI) Discussion Paper No. 849.

[18] Dhanya, P. and Ramachandran, A. 2016. Farmers' perceptions of climate change and the proposed agriculture adaptation strategies in a semi arid region of south India. Journal of Integrative Environmental Sciences 13(1): 1-18,

[19] Raghuvanshi, Rupan and Ansari, M. A. 2016. Farmer's Awareness about Climate Change and Adaptation Practices: A Review. Research \& Reviews: Journal of Agricultural Science and Technology 5(3): 41-51. 